\title{
MAAM PROJECT - HOW DIGITAL LEARNING CAN BRING LIFE INTO THE WORKPLACE
}

\author{
Elisa Vimercati, Francesca Cirianni, MAAM Research \& Development team, Italy
}

\section{Abstract}

Moving from conflicted situation between one's own roles and life experiences to the synergy allows people to have greater awareness of their personal resources and to apply them in all areas of their lives. But how does this happen, in what way? How do people experience it?

This is the question and objective behind the MAAM project. The research uncovers how digital innovation can build new bridges between people's life experiences and the workplace. The research starts from the experience of motherhood, which is paradoxical in its nature on one hand unleashes energy, strength and competencies in the woman, on the other hand it is often perceived as a condition of fragility (physical, psychological) and is not recognized as a bearer of skills at the workplace.

The MAAM project is scientifically based on theories such as role accumulation, positive spillover, generativity, experiential learning and enriches them with two original views: lifebased learning, that postulates that life is in itself one of the richest learning sources, and transilience, a meta-competence that identifies people's ability to actively bring resources and skills from one life domain to another and vice versa. This is an action-research project, with the aim to investigate and simultaneously activate the development of personal resources and soft skills in people.

This objective is achieved through an innovative digital platform that guides the woman in a process of self-reflection and awareness on different topics: the relationship with her identity and her own desires; the caretaking experience with the child and other people; the ways of listening, observing and empathizing and the consequences towards herself, others and the environment; the dynamics of delegation and decision making; the discovery of own "superpowers" and the reflection on the changes taking place.

The research summarizes the results of the digital platform for the first 19 months and has been focused on mothers' experience. It has the aim of investigating the impact of motherhood on the personal development and the soft skills of the women, highlighting which resources are active, which behaviours are adopted, how women perceive their roles and deal with the changes that comes with maternity. This is part of a broader framework, which has been starting to investigate / activate personal development and soft skills in fathers and whose aim is to investigate how caretaking activities trigger people's personal 
development and embed them with soft skills that can be used in every area of life, including workplace.

\section{Current setting and theory}

\section{Current setting}

The relevance of the research derives from two factors: maternity being considered as a period of crisis at the workplace and a national dramatic scenario: female employment in Italy is among the lowest in Europe (48.9\% in 2017 against an EU average 62.4\% - Istat data, Annual Report 2018); the socio-economic participation of women in 2017 remains dramatically low and ranks 118 out of 149 countries (Global Gender Gap Report 2018); over one woman in 5 does not return to work after maternity leave $(22.4 \%$, a value that rises to $30 \%$ if all mothers are considered - (Istat, Chamber Hearing, 8 October 2015); the fertility rate continues to be among the lowest in Europe: 1.34 children per woman in 2016 (EU average 1.6) (Eurostat, 2017).

This scenario clearly shows how there is a large part of the population that is left out of the labour market, or on the contrary - in order to remain, sometimes decides to renounce having more children due to evident difficulties in reconciling family and work commitments.

For this reason, women, often responsible for caring for people, represent a large part of underused human capital, both in terms of non-full participation in the labour market and lack of full appreciation of their potential for the benefit of society.

The MAAM project is part of this big picture of cultural change: a path that enhances the educational potential of motherhood and transforms this period into an occasion for the development of new skills and a stronger and more complex identity, becoming a driving force for personal and professional growth.

\section{Theory and MAAM method}

The theory behind MAAM starts from the studies on family and work interactions, theories studying the impact of covering multiple roles on the individual and has its theoretical basis mainly in the following topics: Role Theory (Barker, 1999), Role Conflict (Goode, 1960) and Role Facilitation (Sieber, 1974; Marks, 1977).

The theories of the role accumulation demonstrate how covering several roles leads to personal strength, development and enrichment instead of struggling to balance the different areas of life the person is involved in (Ruderman et al., 2002). MAAM vision is based on it this is a way of understanding life and work that is relevant and involves both men and women after becoming parents. For MAAM the aim is not to reach conciliation or even balance, but to have synergy between the different areas of life. Resources only "overflow" between the different roles only if we recognize the synergy between the parts of our life holding them together and strengthening them mutually. 
As role accumulation theory states that the whole person is more than the sum of the parts and that participation in some roles can generate resources for use in others. The MAAM method stimulates, makes people aware and triggers this positive spillover ("positive overflow") from maternal caretaking (but not only) to work and vice versa. MAAM is enhancing the educational potential of parenting experience and transforming the experience of parenting in a tool for professional development. It is achieved by concept of transilience, coined as a combination of two words - transition and resilience (Vitullo \& Zezza, 2014). Transilience is a meta-competence that is exercised when your skills, energies, emotional resources flow from one role to another. "What we call resources, involvement and emotional gratification emerge from every role. If it is true that these three elements can be a useful way to create alliances between work and family, it must be kept in mind that they work for this purpose only if they are used with intelligence" (Friedman \& Greenhaus, 2000). For the transilience to be activated, the individual should be aware of two things- his/her agency to act and the positive impact transilience can have on the soft skills at his/her disposal.

Development of these skills is achieved through life-based learning (Staron, Jasinski, \& Weatherley, 2006), a model of learning that starts from experiential learning (Kolb, 1984) and brings the awareness that the complexity of today's work requires new paradigms for professional development. Thus, life becomes a training ground after it is recognized so by an adult who learns, accepts and internalizes this experience.

With MAAM this activation happens through a digital platform rich in multimedia contents, structured as a pathway guiding person before, during and after childbirth. This way, the platform links the experience of parenthood to the specific soft skills, making parents aware and supporting them in the discovery and use of transilience.

At the digital level, MAAM is an environment consisting of three areas: the community (for networking and peer-coaching), the personal area (for self-assessment) and the training ground for the competencies, where through positive examples, open-ended questions designed to trigger reflection and practical exercises parents are guided to discover the extraordinary life experience they are living; they discover their own resources, making them visible to themselves, available to be used and transferred to other contexts of their lives, specifically - to the workplace.

\section{Method and sampling}

\section{Object of survey, approach and methodology}

In this study we have analysed a series of speeches starting from a key message, which is summarized in the name of the product itself - MAAM, whose name originally came out of the acronym "Maternity As A Master". This key message (maternity seen as a master) is refrained throughout the digital pathway and stimulates the self-reflection of women. 
Speeches that can be used as arguments to define points of view, narratives to build the Selfidentity, reflections that explore their emotions, relationships and behaviours (cfr. Mantovani, 2008; pp.15-16; pp.41-47; pp.51-55).

Which methodology proves to be best for this particular text that triggers reactions and thoughts? Our resolution was the adoption of an empirical approach that combines two methodologies and perspectives of qualitative analysis: grounded theory and speech analysis. Following the grounded theory, the textual corpus was subjected to theoretical sampling and followed by codification.

Phases of Analysis:

- Theoretical sampling and choice of exercises, with consecutive adjustments as the analysis proceeds.

- Reconstruction of textual context by collecting the following information for each analysed exercise:

- Starting content;

- Stimuli in the form of questions;

- Set of answers.

- Codification: splitting the speech, identification of recurrent "patterns" and key elements, clustering and analysis based on the frequency (how often they appear in the speech) and intensity (with what force they appear in the speech).

- First categorization - constructing categories based on the answers and words coming from women themselves.

- Second categorization and re-elaboration of the categories - definition of an overall "grounded" design based on the data and comparison of the primary theory.

In the coding phase the categories borrowed from the speech analysis will be used in correspondence with Halliday's systemic-functional grammar (SFG): particularly the concepts of: density and frequency corresponding to the "weight" of the individual items in the speech (see Halliday, Spoken language and written language, 1992; pp.117-127); the concepts of positive and negative polarity (see Halliday, Halliday's Introduction to Functional Grammar, 2014; pp.22-23); the concepts of the field, tenor and mode pertaining to three levels of analysis: "what happens" (field), "who takes part in the situation" (tenor), "what role does the language have" (mode) (cf. Halliday, Spoken language and written language, 1992; p.84).

\section{Sampling}

The period under review includes a period of 19 months, from 30 July 2015 to 26 April 2017. The analysis has covered 20 exercises of a textual corpus that counts in total 152 focused questions, 2800 answers, 70.000 words (69.143). The exercises with the most answers have an average of 100-150 up to 200-290 responses; those with the least number of answers have an average of 25-40 answers. The average response rate - the ratio between those who read the content and those who answered the questions - exceeds $50 \%$, with peaks of 70 to $90 \%$. The 
people who responded to the exercises were 745 women from all over Italy, working at 10 different companies.

\section{Analysis and results}

Analysis shows that motherhood is an experience that empowers and frees personal development and soft skills and in order to trigger this experience it is needed to have:

- $\quad$ an initial positive message (imprinting);

- a guidance to self-reflection.

This lead to two things: skills enablement and the activation of transilience, the metacompetence that is exercised when skills, energies, emotional resources flow from one role to another.

\section{Skill enablement}

The most extensive series of exercises are related to soft skill identification and their practice. Women are triggered to understand their own peculiar strategies, and the particular role that caretaking plays in them. Caretaking helps woman to develop skills such as empathy, observation and listening as the basis for all of them is a strong desire to understand the child and satisfy his/her needs.

The result? A better environment, both in relationships and in one's own experience and emotions.

\section{Experience the delegation (example)}

Some behaviours are hard to acquire: being able to laugh at one's own mistakes and delegating are among those "hard to get" behaviours. But, especially with delegation, after one's own experience with delegation, and even though women do not always have positive experiences with delegation, the result is of great relief.

"My daughter forced me to delegate; the needs forced me to delegate".

Motherhood breaks known patterns and habits and, in doing so, it obliges the woman to leave certain things for others. It therefore enhances a predisposition to change.

Here is how the woman experiences the delegation. The reflection exercise is guided by four questions, each describing the delegation mechanism:

"Try to do an experiment. Think of an activity that you struggle to delegate and write it below:"

"Now choose a person who, by virtue of his/her characteristics, could carry out this activity for you and write his/her name:" 
"Try to overcome your fear and ask for help from this person. Then he/she will tell you how things went. Did he/she do the same things you would have done? “

"Are there any things that surprised you positively? Do you feel more relieved knowing you can count on him/her? "

\section{Try to experiment. Think of an activity that you struggle to delegate and write it below:}

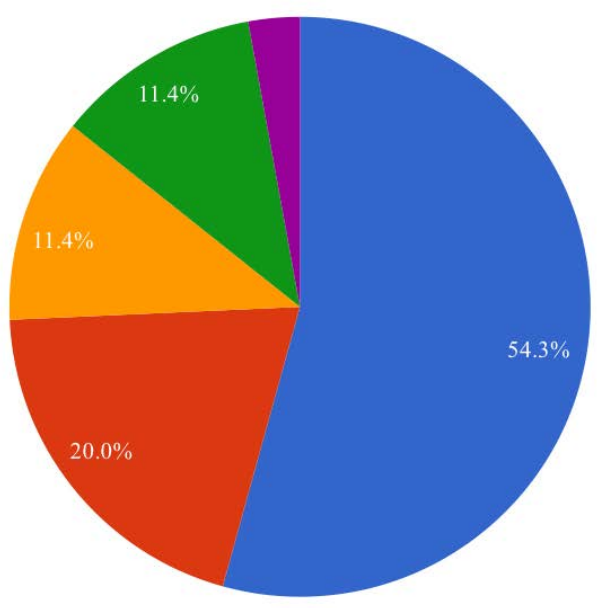

Caretaking of children

Caring for house

Work

Other, general or personal situations

Nothing

Figure 1. Tasks to be delegated

"Try to experiment. Think of an activity that you struggle to delegate and write it below:"

Now choose a person who, by his/her characteristic, could carry out this activity in your place and write his/her name:

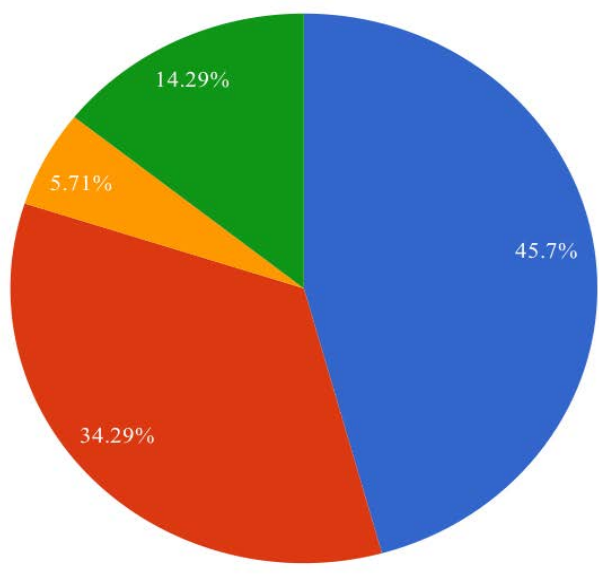

Indicates family member

- Indicates name of someone, specific role of that person

Indicates someone else

Does not respond

Figure 2. Person to whom to delegate

"Now choose a person who, by his/her characteristic, could carry out this activity in your place and write his/her name:" 
Try to overcome your fear and ask for help from this person. Then he/she will tell you how everything went. Did he/she do the same things you would have done?

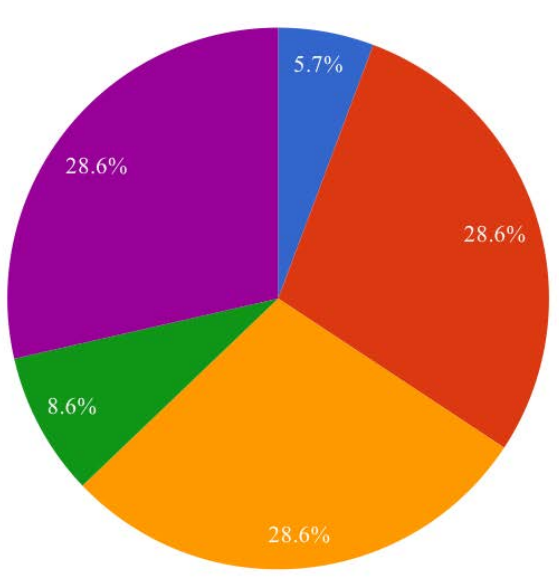

Yes, and even better

Yes

Almost, not exactly, not everything, yes, but in the different way

No

Doesn't know/Doesn't answer

Figure 3. Wait

"Try to overcome your fear and ask for help from this person. Then he/she will tell you how everything went. Did he/she do the same things you would have done?"

Is there anything that surprised you positively? Do you feel more relieved knowing you can count on him/her?

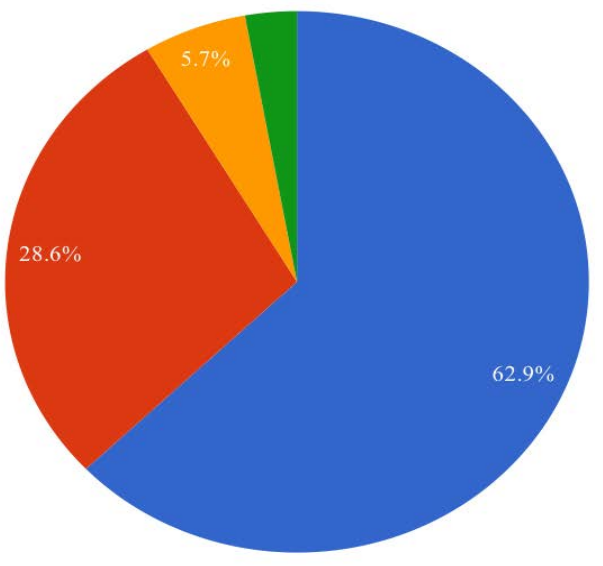

Absolutely yes

Doesn't respond

No (I was aware of his/her capacities)

A bit relieved

Figure 4. Final realization

"Is there anything that surprised you positively? Do you feel more relieved knowing you can count on him/her?"

How does the delegation work?

- The most important and vital activities for women are delegated: childcare, care for the home, work tasks.

- The person to whom to delegate is chosen carefully and it's a trusted person: a partner, one of the parents, a colleague or a friend. 
- Reflecting on how the delegated activity is performed, women discover new strategies and solutions - In half of the cases the person "does the same things", in others performs "even better".

- In terms of attitude and emotions there is a certain difficulty in delegating and leaving someone else in charge. But in almost all of the cases, the result is relief.

\section{Transfer of skills and transilience}

What is transilience? It is the "meta-competence" that allows skills and energies to flow naturally from one area of life to another.

If we look back over the exercises just analysed, we will see how the woman is, and wants to be, present to herself in all areas of her life. She wants to live all her roles, every nuance of her identity and every power of her skills.

Welcome Transilience (example)

Which soft skills do mothers train the most? Relational and organizational soft skills appear to be the most trained and transferred from one area to another.

\section{Okay, Let's practice! Choose a competence that you feel to have trained the most and write it here:}

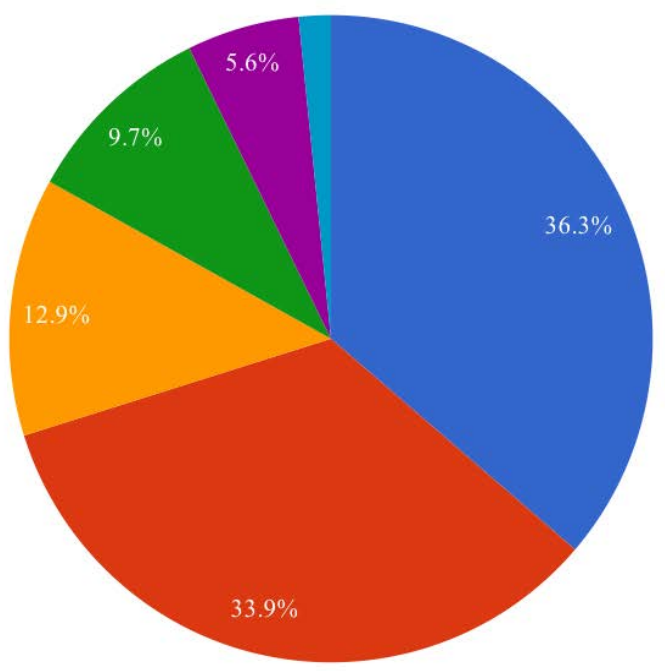

Relational:

- Organizational

Cognitive

Soft

- Managerial

other

Figure 4.

In fact, if we divide soft skills mostly picked up by mothers into macro categories, the order is as follows:

- Relational: 36\%;

- Organizational: 34\%;

- Cognitive: $13 \%$;

- Soft: $10 \%$; 
- Managerial: 6\%.

Going into detail, the most trained skills are organization and planning, management of interpersonal relationships, problem solving; followed by listening, time and priority management and flexibility.

What is the impact of the training? What are the consequences:

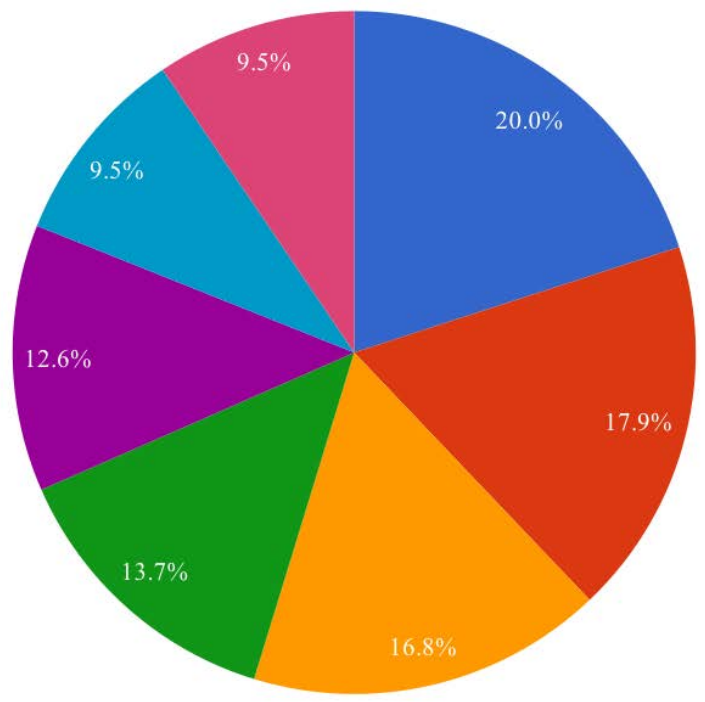

The result is brought home

Relationships improve

You do a lot of things in a short time / with less effort

There is satisfaction - with yourself and with others

Problems are solved

The trust in others is achieved

Positive environment

Figure 5.

What happens when women train skills?

- The result is brought home (20\%);

- Relationships improve (17.9\%);

- You do a lot of things in a short time / with less effort (16.8\%);

- There is satisfaction - towards yourself and towards others (13.7\%);

- $\quad$ Problems are solved (12.6\%);

- The trust in others is achieved (9.5\%);

- Positive environment (9.5\%).

\section{Conclusion}

The following results emerge from the analysis:

- Questions influence answers, and it's like the mirror shapes what is seen inside it. Thus, in this analysis we see that using a positive message generates positivity: women experience positive emotions, are positively surprised by reversing the prospect of their motherhood from a "problem" to a "professional resource".

- Women enrich the way they live their roles, have aspirations and the desire to be "present" in all areas of their lives. 
- If women become aware of their resources and behaviours, they strengthen their soft skills.

As a proof of this, we did a survey and asked the women to assess how much they used the 12 soft skills before and after maternity: the result of the survey shows an average $11 \%$ improvement in soft skills before and after maternity.

Motherhood is a life experience that liberates strength, resources and skills in women. It happens because this experience fully involves woman - her will, identity and desires.

It involves her will: many of the positive changes, such as listening, empathy, the management of unexpected events, complex situations and emergencies are carried out because there a great will in the woman to listen, understand, manage situations and solve problems.

It involves her identity: an identity which, in the transition to the maternal-generative phase becomes both unitary and complex, more rich and multifaceted. Woman remains a woman, a set of desires for personal and professional fulfilment but at the same time she is a mother. The woman-mother is a duality which despite the moments of conflict (expressed in fear, fatigue, tiredness), is mostly experienced and perceived as ONE, and progressively enriched by all the experiences and areas of both private life and work: to prove that the accumulation and synergy between the roles is not an abstraction but a natural condition of the human being.

The effects are multiple.

The force gives the woman more security, courage and positivity.

In turn, the woman becomes more capable of making good use of time and resources available, of optimizing time and priorities and finding unexpected solutions.

There's more trust where this relationship goes both ways - from the woman towards herself and towards others, and from others towards the woman (she becomes a point of reference for those around her).

Care softens the sometimes "stiffened" mechanisms of relationships. The will to understand the child and to satisfy his/her needs is the engine that enhances the skills of listening, attention, and empathy. All of these is reflected on the woman, on the people around her and the way she acts, both at home and at work.

The caretaking, while being the main source to activate the will, is also the element that guides decision-making: women's decisions of wanting good for herself and for others (to avoid negative consequences for herself and other people around her), her desire to make right decision, look for the solution.

Finally, caretaking is what makes women more "powerful". A power made of the ability to simplify, decide, manage people and situations. A power made of strength, commitment, 
tenacity. A power made of intuition, listening, presence, attention. A power made of calm, patience, sweetness, empathy.

This happens in all the contexts that the woman lives and in which she wants to "be", to affirm her own identity, her own desires and her abilities.

\section{References}

Allen, T. D. (2012). The work and family interface (review of work-family literature). In S. W. J. Kozlowski (Ed.), The Oxford Handbook of Organizational Psychology (pp.1163-1198). Oxford University Press.

Barker, R. L. (1999). The social work dictionary (4 ${ }^{\text {th }}$ ed.). Washington, DC: NASW Press.

Donadio, A. (2017). HRevolution. HR nell'epoca della social e digital transformation. Franco Angeli.

Eurostat (2017). Fertility Statistics. Retrieved from http://ec.europa.eu/eurostat/statisticsexplained/index.php/Fertility_statistics

Friedman, S. D., \& Greenhaus, J. H. (2000). Work and Family: Allies or Enemies? Oxford University Press.

Goode, W. J. (1960). A theory of role strain. American Sociological Review, 25, 483-496.

Halliday, M. A. K. (1992). Lingua parlata e lingua scritta. La Nuova Italia.

Halliday, M. A. K. (2014). Halliday's Introduction to Functional Grammar (4 $4^{\text {th }}$ ed.). Revised by Christian M.I.M. Matthiessen. Routledge.

Istat (2015). Indagine conoscitiva sull'impatto in termini di genere della normativa previdenziale e sulle disparità esistenti in materia di trattamenti pensionistici tra uomini e donne, Audizione presso l'XI Commissione Lavoro Pubblico e privato della Camera dei Deputati. Retrieved from http://www.istat.it/it/files/2015/10/A-Audizione-commissionelavoro-camera_8-

ottobre.pdf?title $=$ Normativa + previdenziale $+\mathrm{e}+$ disparit $\% \mathrm{C} 3 \% \mathrm{~A} 0+\mathrm{di}+$ genere ++09\%2Fott\%2F2015+-+Testo+integrale.pdf

Istat (2018). Annual Report 2017. Retrieved from https://www.istat.it/it/files//2018/06/AnnualReport2018.pdf

Istat (2019). Employed and unemployed - December 2018. Retrieved from https://www.istat.it/it/files//2019/01/Employment-and-unemployment_201812.pdf

Kolb, D. A. (1984). Experiential learning. Experience as the Source of Learning and Development. Prentice Hall

Marks, S. R. (1977). Multiple role and strain: Some notes on human energy, time and commitment. American Sociological Review, 42, 921-936.

Mantovani, G. (2008). Analisi del discorso e contesto sociale. Il Mulino. 
Rosina, A., \& Zezza, R. (2016). Generare futuro - Cultura e politiche per tornare ad essere un paese vitale. Retrieved from https://voltaitalia.org/wp-content/uploads/2016/05/VoltaPaper-03-natalita.pdf

Ruderman, M. N., Ohlott, P. J., Panzer, K., \& King, S. N. (2002). Benefits of multiple roles for managerial women. The Academy of Management Journal.

Save the Children (2017). Le equilibriste. La maternità tra ostacoli e visioni di futuroRapporto mamme 2017. Retrieved from

https://www.savethechildren.it/sites/default/files/files/uploads/pubblicazioni/leequilibriste-la-maternita-tra-ostacoli-e-visioni-di-futuro.pdf

Sieber, S. D. (1974). Toward a theory of role accumulation. American Sociological Review, 39, 567-578.

Staron, M., Jasinski, M., \& Weatherley, R. (2006). Life Based Learning. A strength based approach for capability development in vocational and technical education. Research Project 'Designing Professional Development for the Knowledge Era', TAFE NSW ICVET with Department of Education, Science and Training (DEST).

Tarozzi, M. (2008. Che cos'è la grounded theory. Carocci.

Vitullo, A., \& Zezza, R. (2014). MAAM. La maternità è un master che rende più forti uomini e donne. BUR. 